\title{
BMJ Open Comparing the prevalence of multimorbidity using different operational definitions in primary care in Singapore based on a cross-sectional study using retrospective, large administrative data
}

\author{
Yi An Janis Lee (1) , ${ }^{1}$ Ying Xie, ${ }^{2}$ Poay Sian Sabrina Lee (i) , ${ }^{2}$ Eng Sing Lee (i) ${ }^{1,2}$
}

To cite: Lee YAJ, Xie Y, Lee PSS, et al. Comparing the prevalence of multimorbidity using different operational definitions in primary care in Singapore based on a cross-sectiona study using retrospective, large administrative data. BMJ Open 2020;10:e039440. doi:10.1136/ bmjopen-2020-039440

- Prepublication history and supplemental matarial for this paper are available online. To view these files, please visit the journal online (http://dx.doi. org/10.1136/bmjopen-2020039440).

Received 15 April 2020 Revised 18 November 2020 Accepted 19 November 2020

D) Check for updates

(C) Author(s) (or their employer(s)) 2020. Re-use permitted under CC BY-NC. No commercial re-use. See rights and permissions. Published by BMJ.

${ }^{1}$ National Healthcare Group Polyclinics, Clinical Research Unit, National Healthcare Group, Singapore

${ }^{2}$ Lee Kong Chian School of Medicine, Nanyang

Technological University,

Singapore

Correspondence to

Dr Eng Sing Lee;

Eng_Sing_LEE@nhgp.com.sg

\section{ABSTRACT}

Objectives Multimorbidity is a norm in primary care. A consensus on its operational definition remains lacking especially in the list of chronic conditions considered. This study aimed to compare six different operational definitions of multimorbidity previously reported in the literature for the context of primary care in Singapore. Design, setting and participants This is a retrospective study using anonymised primary care data from a study population of 787446 patients. We defined multimorbidity as having three or more chronic conditions in an individual. The prevalence of single conditions and multimorbidity with each operational definition was tabulated and standardised prevalence rates (SPRs) were obtained by adjusting for age, sex and ethnicity. We compared the operational definitions based on (1) number of chronic diseases, (2) presence of chronic diseases of high burden and (3) relevance in primary care in Singapore. IBM SPSS V.23 and Microsoft Office Excel 2019 were used for all statistical calculations and analyses.

Results The SPRs of multimorbidity in primary care in Singapore varied from $5.7 \%$ to $17.2 \%$. The lists by Fortin et al, Ge et al, Low et al and Quah et al included at least 12 chronic conditions, the recommended minimal number of conditions. Quah et al considered the highest proportion of chronic diseases $(92.3 \%)$ of high burden in primary care in Singapore, with SPRs of at least 1.0\%. Picco et al and Subramaniam et al considered the fewest number of conditions of high relevance in primary care in Singapore. Conclusions Fortin et als list of conditions is most suitable for describing multimorbidity in the Singapore primary care setting. Prediabetes and 'physical disability' should be added to Fortin et al's list to augment its comprehensiveness. We propose a similar study methodology be performed in other countries to identify the most suitable operational definition in their own context.

\section{BACKGROUND}

Multimorbidity, the co-occurrence of multiple chronic health conditions in a
Strengths and limitations of this study

- Strengths of this study include the utilisation of a large database and the determination of the clinical relevance of a chronic condition through an iterative process.

- Another strength of this study is the employment of a systematic method in the comparison of all six operational definitions.

- The limitations of this study include the utilisation of a single administrative database and the use of a predetermined number of International Statistical Classification of Diseases and Related Health Problems revision 10 codes.

- This study also did not consider the impact of each chronic condition on affected individuals.

single individual, ${ }^{1}$ is a growing norm in primary care. ${ }^{2-5}$ 'Multimorbidity' has often been confused with 'comorbidity'. ${ }^{6}$ Comorbidity describes the simultaneous presence of multiple health conditions when there is an index condition. In contrast, multimorbidity describes the co-occurrence of two or more chronic medical conditions without specifying the index condition. Health outcomes are evaluated based on the interaction and burden of all coexisting chronic conditions. ${ }^{8}$ Advocates of the concept of multimorbidity tend to focus on primary care, where the identification of an index disease is often neither obvious nor useful. ${ }^{9}$

The implications of multimorbidity are significant and widespread. From the patient's perspective, multimorbidity is associated with future functional decline,${ }^{10} 11$ reduced health-related quality of life, ${ }^{10} 12$ inpatient admission and mortality. ${ }^{13}$ From an economic standpoint, multimorbidity is associated with 
increased healthcare utilisation ${ }^{14}$ and healthcare costs. ${ }^{10}$ Single disease clinical practice guidelines (CPGs) that have traditionally been used for the management of chronic diseases are inappropriate in the management of patients with multimorbidity. ${ }^{515-17}$

To this date, there is no consensus on an operational definition of multimorbidity. ${ }^{18-20}$ This definition comprises two components: the list of chronic conditions considered and the cut-off for the number of chronic conditions used to determine the presence of multimorbidity. ${ }^{21}$ The absence of a standardised operational definition has resulted in reported prevalence estimates of multimorbidity in Singapore to range widely from $16.3 \%$ to $89.4 \%^{12} 1422-24$ and has made comparability between published studies impossible. ${ }^{21}$ Wide variations in prevalence estimates also prevent accurate estimations of disease burden and hinder resource distribution for effective disease management. ${ }^{25}$

In 2017, an operational definition comprising 20 chronic conditions/categories of conditions was proposed by Fortin $e t$ al as a common list of conditions for studying multimorbidity in primary care (online supplemental appendix 1-1). ${ }^{21}$ These conditions were selected from a scoping review of relevant studies.

We identified six studies, two by Ge $e t a l^{2326}$ (online supplemental appendix 1-2) and one each by Low $e t a t^{24}$ (online supplemental appendix 1-3), Picco et $\mathrm{l}^{14}$ (online supplemental appendix 1-4), Quah et al ${ }^{12}$ (online supplemental appendix 1-5) and Subramaniam et $a l^{22}$ (online supplemental appendix 1-6), which were published between 2014 and 2019 in Singapore. These studies were identified on Medline Ovid between 2010 and 14 March 2020 and through direct correspondences with the authors (online supplemental appendix 2). Heterogeneity was noted in both the methodologies and lists of chronic conditions used in each study.

The objective of this study was to compare the different operational definitions of multimorbidity previously reported in the literature for the context of primary care in Singapore.

\section{METHODS}

\section{Setting and study population}

The study population was selected between 1 July 2015 and 30 June 2016. During this period, the public primary healthcare sector was organised into two main clusters in Singapore-National Healthcare Group Polyclinics (NHGP) and SingHealth Polyclinics. The two clusters shared 18 polyclinics island-wide, providing governmentfunded subsidised primary care. According to statistics published by the Ministry of Health $(\mathrm{MOH})$, Singapore, 3916771 individuals (approximately 70\% of the 2016 Singapore population ${ }^{27}$ ) consulted a doctor in the polyclinics in 2016. Out of which, $58.9 \%$ attended the NHGP. ${ }^{28}$ The choice to draw data only from the NHGP was based on pragmatic reasons. The participants in this study were multiethnic patients aged 0-99 years old who consulted a doctor in NHGP at least once during the study period. A total of 787446 patients from nine polyclinics were included in this study.

\section{Data source}

Data from the study population were collected from the NHGP Business Intelligence (BI) system. The BI system is an administrative database that captures each patient's consultation episodes and clinical parameters from structured data fields within the electronic medical records (EMRs) for example, blood pressure readings, International Statistical Classification of Diseases and Related Health Problems revision 10 (ICD-10) diagnoses codes and laboratory data. We excluded all patient encounters that did not include an ICD-10 diagnosis code by a physician. Only deidentified data were collected in accordance with the personal data protection act. ${ }^{29}$

\section{Patient and public involvement}

No patients were involved in this study.

\section{Definition of chronic condition and multimorbidity}

We adopted the definition of O'Halloran et al for chronicity of a disease, which is defined as one lasting at least 6 months, with a documented pattern of recurrence or deterioration, and having an impact on an individual's quality of life. ${ }^{30}$

While we acknowledge that most studies have defined multimorbidity using a cut-off of 'two or more' chronic conditions, ${ }^{31}$ in keeping with the WHO's definition of multimorbidity, ${ }^{32}$ we adopted a cut-off of 'three or more' chronic conditions to better identify patients with higher needs. ${ }^{18}$

\section{Determination of prevalence rates of single conditions and multimorbidity}

The prevalence of a disease is defined as the proportion of the population at risk (PAR) that are cases at a point in time. ${ }^{33}$ The PAR is defined as the group of people, healthy or sick, who would be counted as cases if they had the disease of interest. This forms the denominator for the calculation of prevalence. ${ }^{33}$ For this study, the PAR was denoted by individuals aged 0-99 years who consulted a doctor in NHGP at least once during the study period.

For the crude prevalence rate of single conditions, the numerator used was the number of unique patients with the single condition who had consulted a doctor in NHGP at least once during the study period. For the crude prevalence rate of multimorbidity, the numerator used was the number of unique patients with multimorbidity who had consulted a doctor in NHGP at least once during the study period.

Standardised prevalence rates (SPRs) were obtained by adjusting the study population to a standard population by using the direct standardisation method as detailed by Bains. ${ }^{34}$ The 2016 Singapore population was used as the standard population. ${ }^{27}$ Poisson approximation was used to calculate the CIs of $95 \%$. 


\section{Criteria for comparison of operational definitions}

Among the six studies conducted in Singapore, only five unique operational definitions were identified. The two studies by Ge $e t a l^{2326}$ used the same operational definition. We compared six lists of chronic conditions from six different operational definitions of multimorbidity (online supplemental appendix 3) on the same study population. This included the list proposed by Fortin et al that had been developed as a research tool to document the presence of multimorbidity in primary care ${ }^{21}$ (online supplemental appendix 1-1) and the five lists used in the study of multimorbidity in Singapore (online supplemental appendix 1-2 to 1-6). A list of NHGP ICD-10 diagnosis codes was assembled by four senior family physicians based on the aforementioned definition of chronicity. ${ }^{30}$

Fortin et al proposed that an ideal operational definition of multimorbidity should comprise at least 12 chronic diseases, each with a high impact or burden in the population of interest. ${ }^{18}$ Based on this, the comparison of the six operational definitions was focused on (1) the number of chronic diseases considered, (2) presence of chronic diseases of high burden and (3) relevance in the primary care setting in Singapore. We considered a chronic condition to be of significant burden in the primary care if it has an SPR of at least 1.0\%. We tabulated the proportion of chronic diseases with a SPR of at least $1.0 \%$ in each list. The numerator used was the number of chronic conditions with an SPR of at least $1.0 \%$ and the denominator was the total number of chronic conditions in the list. The clinical relevance of a condition was based on consensus reached after iterative discussions between the clinicians, research team members and reference to statistics from the $\mathrm{MOH}$ and local primary care initiatives such as the Chronic Disease Management Programme (CDMP) ${ }^{35}$

Statistics reported by the MOH have consistently ranked hyperlipidaemia, hypertensive disease and diabetes mellitus as the first, second and fourth top condition responsible for polyclinic attendances since 2012. ${ }^{36}$ Hyperlipidaemia constituted $13.8 \%$ of polyclinic attendances in 2018, closely followed by hypertensive disease at $13.2 \%$, acute upper respiratory tract infection at $9.4 \%$ and diabetes mellitus at $9.0 \%$.

The CDMP $^{35}$ was introduced in 2006 to facilitate the provision of care to patients with chronic conditions through the development of evidence-based structured Disease Management Programmes and to reduce out-ofpocket payments for outpatient treatments by allowing patients to draw on their Medisave. The structured Disease Management Programmes facilitate the management of these conditions in the primary care setting. In 2018, the list of chronic conditions included in CDMP was increased to include 20 chronic conditions (online supplemental appendix 4).

\section{Statistical analysis}

The sample size was determined by the number of patients aged 0-99 years who visited the NHGP for at least

\begin{tabular}{|c|c|c|c|}
\hline & Frequency & Percent & Mean age (SD) \\
\hline Total & 787446 & 100.0 & $43.9(0.03)$ \\
\hline \multicolumn{4}{|l|}{ Sex } \\
\hline Female & 400965 & 50.9 & $45.3(0.04)$ \\
\hline Male & 386481 & 49.1 & $42.2(0.04)$ \\
\hline \multicolumn{4}{|l|}{ Ethnicity } \\
\hline Chinese & 537234 & 68.2 & $47.1(0.03)$ \\
\hline Malay & 127501 & 16.2 & $35.1(0.06)$ \\
\hline Indian & 78452 & 10.0 & $39.7(0.08)$ \\
\hline Others & 44259 & 5.6 & $37.1(0.09)$ \\
\hline \multicolumn{4}{|l|}{ Age groups } \\
\hline $0-24$ & 201839 & 25.6 & \\
\hline $25-44$ & 165212 & 21.0 & \\
\hline $45-64$ & 252206 & 32.0 & \\
\hline $65-99$ & 168189 & 21.4 & \\
\hline
\end{tabular}

one doctor consultation during the study period. We used listwise deletion method for complete case analysis. For descriptive statistics, we described the mean for continuous variables and their respective SD. For categorical variables, we described proportions and their respective CIs where appropriate.

SPRs were obtained by adjusting for age, sex and ethnicity. Age was stratified into four categories-' $0-24$ ', '25-44', '45-64' and '65-99'. Sex was classified into male and female, and ethnicity was categorised into Chinese, Malay, Indian and Others. To compare the SPRs of multimorbidity among age and sex, we tabulated age-stratified, sex-and-ethnicity SPR and sex-stratified, age-and-ethnicity SPR of multimorbidity between the different lists. No overlap of the $95 \%$ CIs for the SPRs among the different lists was considered as statistically significant. IBM SPSS V.23 and Microsoft Office Excel 2019 were used for all statistical calculations and analyses.

\section{RESULTS}

The mean age of the 787446 patients analysed in this study was 43.9 years. Females made up $50.9 \%$ of the patients and the Chinese formed the majority ethnic group at $68.2 \%$. Of the four ethnicities, the Chinese had the highest mean age of 47.1 years. A total of $53.4 \%$ of the patients studied were from the ' $45-64$ ' to '65-99' age groups (table 1 ).

The list recommended by Fortin $e t a l^{21}$ gave the highest SPR of multimorbidity in the study population $(17.2 \%)$. Across the six lists, the SPRs of multimorbidity increased with increasing age. The male sex reported higher SPRs of multimorbidity and the differences between the sexes are statistically significant (table 2 ).

\section{Criterion 1: number of chronic conditions}

A list of 57 NHGP ICD-10 diagnosis codes (online supplemental appendix 5) was matched to the chronic conditions 
Table 2 Comparison of the standardised prevalence rates of multimorbidity among the six lists of chronic conditions

\begin{tabular}{|c|c|c|c|c|c|c|}
\hline & $\begin{array}{l}\text { Fortin et al } \\
2017\end{array}$ & $\begin{array}{l}\text { Ge et al } \\
2018 \text { and } 2019\end{array}$ & $\begin{array}{l}\text { Low et al } \\
2019\end{array}$ & $\begin{array}{l}\text { Picco et al } \\
2016\end{array}$ & $\begin{array}{l}\text { Quah et al } \\
2016\end{array}$ & $\begin{array}{l}\text { Subramaniam et al } \\
2014\end{array}$ \\
\hline Total & $\begin{array}{l}17.2 \\
\text { (17.2 to } 17.3)\end{array}$ & $\begin{array}{l}13.0 \\
(12.9 \text { to } 13.0)\end{array}$ & $\begin{array}{l}14.6 \\
\text { (14.5 to } 14.7)\end{array}$ & $\begin{array}{l}5.7 \\
\text { (5.7 to } 5.8)\end{array}$ & $\begin{array}{l}16.8 \\
(16.7 \text { to } 16.8)\end{array}$ & $\begin{array}{l}5.9 \\
\text { (5.8 to } 5.9)\end{array}$ \\
\hline \multicolumn{7}{|l|}{ Sex } \\
\hline Female & $\begin{array}{l}16.5 \\
\text { (16.4 to } 16.6)\end{array}$ & $\begin{array}{l}11.7 \\
\text { (11.7 to } 11.8)\end{array}$ & $\begin{array}{l}13.5 \\
\text { (13.4 to } 13.6)\end{array}$ & $\begin{array}{l}5.4 \\
\text { (5.4 to } 5.5)\end{array}$ & $\begin{array}{l}16.0 \\
(15.9 \text { to } 16.1)\end{array}$ & $\begin{array}{l}5.6 \\
\text { (5.5 to } 5.6)\end{array}$ \\
\hline Male & $\begin{array}{l}18.0 \\
(17.9 \text { to } 18.1)\end{array}$ & $\begin{array}{l}14.3 \\
(14.1 \text { to } 14.4)\end{array}$ & $\begin{array}{l}15.8 \\
\text { (15.7 to } 15.9)\end{array}$ & $\begin{array}{l}6.0 \\
\text { (5.9 to } 6.1)\end{array}$ & $\begin{array}{l}17.6 \\
(17.4 \text { to } 17.7)\end{array}$ & $\begin{array}{l}6.2 \\
(6.1 \text { to } 6.2)\end{array}$ \\
\hline \multicolumn{7}{|c|}{ Age groups } \\
\hline $0-24$ & $\begin{array}{l}0.08 \\
\text { (0.07 to } 0.10)\end{array}$ & $\begin{array}{l}0.02 \\
(0.02 \text { to } 0.03)\end{array}$ & $\begin{array}{l}0.04 \\
\text { (0.03 to } 0.05)\end{array}$ & $\begin{array}{l}0.01 \\
\text { (0.01 to } 0.01 \text { ) }\end{array}$ & $\begin{array}{l}0.10 \\
(0.08 \text { to } 0.11)\end{array}$ & $\begin{array}{l}0.02 \\
(0.01 \text { to } 0.02)\end{array}$ \\
\hline $25-44$ & $\begin{array}{l}4.0 \\
\text { (3.9 to } 4.1)\end{array}$ & $\begin{array}{l}2.2 \\
\text { (2.1 to } 2.3)\end{array}$ & $\begin{array}{l}2.8 \\
(2.7 \text { to } 2.9)\end{array}$ & $\begin{array}{l}0.5 \\
(0.5 \text { to } 0.5)\end{array}$ & $\begin{array}{l}3.6 \\
\text { (3.5 to } 3.7 \text { ) }\end{array}$ & $\begin{array}{l}0.6 \\
(0.6 \text { to } 0.7)\end{array}$ \\
\hline $45-64$ & $\begin{array}{l}28.5 \\
\text { (28.3 to } 28.7 \text { ) }\end{array}$ & $\begin{array}{l}20.2 \\
\text { (20.0 to } 20.4 \text { ) }\end{array}$ & $\begin{array}{l}23.2 \\
\text { (23.0 to } 23.4 \text { ) }\end{array}$ & $\begin{array}{l}7.8 \\
\text { (7.7 to } 7.9)\end{array}$ & $\begin{array}{l}27.7 \\
\text { (27.5 to } 27.9)\end{array}$ & $\begin{array}{l}8.1 \\
(8.0 \text { to } 8.2)\end{array}$ \\
\hline $65-99$ & $\begin{array}{l}60.9 \\
(60.5 \text { to } 61.2)\end{array}$ & $\begin{array}{l}50.9 \\
(50.5 \text { to } 51.2)\end{array}$ & $\begin{array}{l}55.4 \\
\text { (55.0 to } 55.7 \text { ) }\end{array}$ & $\begin{array}{l}26.1 \\
\text { (25.9 to } 26.4 \text { ) }\end{array}$ & $\begin{array}{l}60.1 \\
\text { (59.7 to } 60.4)\end{array}$ & $\begin{array}{l}26.3 \\
\text { (26.1 to } 26.6)\end{array}$ \\
\hline
\end{tabular}

in these six lists. Among the 20 conditions/categories of conditions proposed by Fortin et al, ${ }^{21}$ only 19 of them could be matched to the corresponding NHGP ICD-10 codes. We excluded the condition 'chronic musculoskeletal condition causing pain or limitation' from the list as the corresponding ICD-10 code was not reliably coded at our primary care setting. Similarly, as only 13 out of 14 conditions/categories of conditions proposed by Quah et $a l^{12}$ could be matched to corresponding NHGP ICD-10 codes, the condition 'back problems' was excluded from the list.

Low et $a l^{24}$ proposed a total of 48 chronic conditions, eight of which-'hip fracture', 'nephrosis', 'respiratory failure', 'secondary hypertension', 'spine fracture', 'coronary artery bypass graft', 'percutaneous coronary intervention' and 'kidney transplant' had no corresponding NHGP ICD-10 codes and were excluded from the list. Of the remaining 40 conditions, 16 conditions had overlapping ICD-10 codes. This included chronic conditions such as 'anxiety' and 'general anxiety disorder', which were matched to the same ICD-10 code: F41.1 'anxiety disorder, unspecified' (online supplemental appendix 1-3). These conditions were reclassified to obtain a final list of 31 chronic conditions to avoid double-counting of chronic diseases and overestimation of multimorbidity.

Picco $e t a l^{4}$ and Subramaniam et $a l^{22}$ only considered 10 and 8 conditions, respectively, falling short of the recommended minimal number of 12 chronic conditions. ${ }^{18}$

\section{Criterion 2: prevalence among the primary care population}

We considered a chronic condition to be of high burden in the primary care setting if it has an SPR of at least $1.0 \%$. The list proposed by Quah et $a l^{12}$ had the highest proportion $(92.3 \%)$ of chronic conditions with an SPR of at least $1.0 \%$ (online supplemental appendix 1-5). This was followed by the list by Fortin et $a l^{21}(78.9 \%)$ (online supplemental appendix 1-1), Picco et al ${ }^{14}$ (70.0\%) (online supplemental appendix 1-4), Subramaniam et $a l^{22}$ $(62.5 \%)$ (online supplemental appendix 1-6), Ge et al $t^{2326}$ $(52.9 \%)$ (online supplemental appendix 1-2) and finally Low $e$ t $a l^{24}(41.9 \%)$ (online supplemental appendix 1-3).

\section{Criterion 3: relevance to primary care services}

Hypertensive disease and diabetes mellitus were represented in all six operational definitions, with SPRs of $20.93 \%$ and $11.86 \%$, respectively. Hyperlipidaemia, with the highest SPR of $24.97 \%$, however, was absent in the lists of chronic conditions by Picco et al ${ }^{14}$ and Subramaniam et al..$^{22}$

We compared the chronic conditions under CDMP with the lists of chronic conditions in the six operational definitions. The list of chronic conditions by Low et $a t^{24}$ included all 20 conditions under CDMP. This was followed by Ge $e t a l^{2326}$ and Quah $e t a l,{ }^{12}$ with each considering 17 out of the 20 chronic conditions. Fortin $e t a l^{21}$ considered 15 out of the 20 chronic conditions and Subramaniam et $a l^{22}$ and Picco et $a l^{14}$ only considered 8 and 10 of the 20 conditions, respectively.

\section{DISCUSSION}

\section{Summary of results}

The SPRs of multimorbidity in the primary care setting in Singapore varied widely depending on the operational definition used. The list of chronic conditions proposed by Fortin $e t a l^{21}$ gave the highest SPR of multimorbidity (17.2\%). The lists by Fortin et $a l,{ }^{21}$ Ge et $a l,{ }^{23}{ }^{26}$ Low et $a l^{24}$ and Quah $e t a l^{12}$ included at least 12 chronic conditions with the list by Quah et $a l^{12}$ comprising the highest proportion of chronic diseases $(92.3 \%)$ with an SPR of at least $1.0 \%$ that matched with a NHGP ICD-10 code. The lists by Picco $e t a l^{4}$ and Subramaniam $e t a l^{22}$ did not 
include hyperlipidaemia, a chronic condition of high relevance in the primary care setting in Singapore and both lists considered the fewest number of conditions under CDMP.

\section{Comparison of operational definitions}

Comparing the six operational definitions, it is clear that the lists proposed by Picco et $a l^{14}$ and Subramaniam $e t$ $a l^{22}$ had fallen short on several fronts. Both lists considered less than 12 chronic conditions and have comparatively lower proportions of chronic conditions with SPR of at least $1.0 \%$. In addition, both considered the fewest number of chronic conditions under CDMP and failed to include hyperlipidaemia, which constitutes a large proportion of polyclinic attendances. These shortfalls likely contributed to the low SPRs of multimorbidity tabulated and underestimate multimorbidity in the primary care setting in Singapore.

While Low et al's list ${ }^{24}$ comprised 31 chronic conditions, including all 20 conditions under CDMP, it reported the lowest proportion of chronic diseases $(41.9 \%)$ with an SPR of at least $1.0 \%$. This is likely due to two reasons. The first was that Low $e$ t $a$ ls list ${ }^{24}$ is the longest among the six lists. While Low et $a l^{24}$ included 13 conditions with an SPR of at least $1.0 \%$, (numerator), second only to Fortin et $a l^{21}$ its inclusion of a total of 31 chronic conditions (denominator), resulted in a less discriminating list. Second, the manner in which the list of chronic conditions was classified could be a contributory factor. Low $e t a l^{24}$ had kept 'major depression', 'anxiety', 'schizophrenia' and 'bipolar disorder' as four separate chronic conditions (online supplemental appendix 1-3), while other studies such as that by Quah et $a l^{12}$ had grouped them under a single chronic condition category-'psychiatric conditions' (online supplemental appendix 1-5). When considered individually, only the chronic condition 'major depression' had an SPR of at least $1.0 \%$. While Low et al's list ${ }^{24}$ is the most comprehensive, the presence of chronic conditions with overlapping ICD-10 codes prior to reclassification and the large number of chronic conditions with no corresponding NHGP ICD-10 codes make it less ideal as an operational definition for use in the primary care setting in Singapore.

The list by Ge et al, ${ }^{23}{ }^{26}$ which comprised 17 chronic conditions and considered a large number of chronic conditions under CDMP, also had a low proportion of chronic diseases $(52.9 \%)$ with an SPR of at least $1.0 \%$. Ge et $a t^{2326}$ had likewise considered the psychiatric diseases individually (online supplemental appendix 1-2) as opposed to grouping them as a single chronic condition. In addition, Ge et al $\mathrm{s}$ list ${ }^{23}{ }^{26}$ did not include conditions commonly seen in primary care such as thyroid conditions and diseases of the gastrointestinal tract, which were present in Fortin $e t a l^{21}$ (online supplemental appendix 1-1) and Quah et al s lists $^{12}$ (online supplemental appendix 1-5). 'Thyroid disorder (Fortin et $a l^{21}$ )/thyroid diseases (Quah $e t a l^{12}$ )' have an SPR of 2.36\%. 'Chronic hepatitis (Fortin $e t a l^{21}$ )' and 'stomach problem (reflux, heart burn or gastric ulcer) (Fortin $e t a l^{21}$ )' have SPRs of $3.02 \%$ and $2.52 \%$, respectively, while 'gastrointestinal diseases (Quah et $a l^{12}$ )' have an SPR of $5.76 \%$. The list proposed by Ge $e t$ $a l^{2326}$ is thus not ideal as the exclusion of these chronic conditions would underestimate multimorbidity in the Singapore primary care setting.

Quah et als list ${ }^{12}$ of 13 conditions, encompassing 17 CDMP conditions, comprised the largest proportion of chronic conditions $(92.3 \%)$ with SPRs of at least $1.0 \%$. This is contributed by two reasons. First, Quah $e t a l^{12}$ had included the chronic condition 'physical disability', which had a SPR of $1.05 \%$ and was absent in all the other five lists. Second, Quah et $a l^{12}$ had classified chronic diseases affecting similar organ systems into a single chronic condition category (online supplemental appendix 1-5). For example, several ICD-10 conditions such as Parkinson's disease, dementia, epilepsy and stroke were all classified under a single category 'neurological conditions'. While we acknowledge that individuals who suffer diseases of the same organ system often follow-up with the same specialist and treatment options are often complementary and hence the rationality behind this manner of classification, ${ }^{37}$ it is of our view that this is not always applicable to all chronic conditions of the same organ system. For example, in Parkinson's disease, the focus of care is on maintaining functional capabilities, while in epilepsy, care is focused on the avoidance of seizure triggers and seizure first aid. This manner of classification, as adopted by Quah at el., ${ }^{12}$ risks overlooking individuals who require greater care and would fail to give a discerning estimate of multimorbidity. It is of our view that clinical judgement should be exercised in defining 'disease entities' taking into account the care needs of each chronic condition.

While the list of 19 chronic conditions proposed by Fortin $e t a l^{21}$ captured fewer chronic conditions under CDMP and had a lower proportion of chronic conditions $(78.9 \%)$ with a SPR of at least $1.0 \%$ compared with that by Quah $e t a l,{ }^{12}$ its inclusion of key chronic conditions of relevance to primary care makes it most suitable as an operational definition for use in the primary care setting in Singapore. Fortin $e t a l^{21}$ included the chronic condition 'chronic urinary problem', which was matched to the ICD-10 code 'hyperplasia of prostate'. The SPR tabulated was $1.07 \%$ and benign prostatic hyperplasia is also recognised under CDMP, underscoring its importance in the population. In addition, Fortin $e t a l^{21}$ considered the chronic condition 'osteoporosis', a chronic disease recognised under CDMP. While the SPR tabulated for 'osteoporosis' stands at $0.57 \%$, this is likely to increase in the future in view of Singapore's rapidly ageing population. ${ }^{38}$

\section{Proposing a new operational definition of multimorbidity}

When applied to the primary care population in Singapore, the list proposed by Fortin et $a l^{21}$ had comparatively outshone the others based on the aforementioned criteria. 
We propose the use of a modified list of chronic conditions adapted from Fortin $e t a l$ s list $^{21}$ for use in the primary care setting in Singapore (online supplemental appendix 6). We suggest the inclusion of prediabetes (ICD-10 codes: E09 and E099) under the chronic condition 'diabetes' and the addition of the chronic condition 'physical disability' to Fortin et al's existing list of chronic conditions $^{21}$ to increase its comprehensiveness.

The relevance of prediabetes in Singapore is indisputable with the Singapore government placing greater emphasis on diabetes management and aggressive intervention for individuals with prediabetes. ${ }^{39}$ Prediabetes is also recognised under CDMP and has an SPR of 3.65\% $(3.61,3.69)$. The inclusion of prediabetes under the chronic condition 'diabetes' increased the SPR from $11.86 \%$ to $14.28 \%$ (14.20, 14.35$)$.

The inclusion of 'physical disability', with an SPR of $1.05 \%$, which includes the ICD-10 code 'hearing loss' is important in the context of Singapore's ageing population as the prevalence of hearing impairment has been reported to increase with age and has serious ramifications physically, mentally, socially and financially for affected individuals. ${ }^{40}$

We acknowledge that Fortin et $a l^{21}$ did not recognise several conditions under CDMP (online supplemental appendix 4), namely, 'schizophrenia', 'bipolar disorder', 'Parkinson's disease', 'epilepsy' and 'psoriasis', however, the SPRs of each of these chronic conditions are low and are unlikely to result in much variation in the prevalence estimates of multimorbidity. In addition, in Singapore, these chronic conditions are still largely managed by their relevant specialities and do not form a large proportion of primary care attendances.

With the proposed new operational definition, we calculated the SPR of multimorbidity to be $18.1 \%$. The pattern of multimorbidity across the different sex, ethnicity and age groups remains consistent with that of Fortin $e t a l \mathrm{~s}^{21}$

\section{Strengths of our study}

Our study leveraged on the utilisation of a large database on which the six different operational definitions were consistently applied. The determination of the clinical relevance of a chronic condition was also achieved through an iterative process, with discussions held among clinicians and research team members. In addition, a systematic method was employed in the comparison of all six operational definitions.

\section{Limitations of our study}

Our study has several limitations. First, we only used data from a single administrative source-the EMRs. The use of a single data source risks underestimating the prevalence estimates of chronic conditions. ${ }^{41}$ Furthermore, the utilization of EMRs relies heavily on accurate and consistent data reporting. This limitation was, however, mitigated by the use of standardised ICD-10 codes. Second, the number of ICD-10 codes depicting chronic conditions is fixed and predetermined in our EMRs. Ten chronic conditions/ categories of conditions could not be reliably coded with the NHGP ICD-10 codes. This included the chronic condition proposed by Fortin et $a l^{21}$ "chronic musculoskeletal condition causing pain or limitation', a common report in the primary care setting. ${ }^{12}$ The fixed number of NHGP ICD-10 codes available also limited the inclusivity of chronic conditions such as 'physical disability', which only included the ICD-10 codes 'hearing loss' and 'congenital malformation of the musculoskeletal system'. The available list of ICD-10 codes may change as we move on to the new generation EMR system in the future. Third, our study reports low SPRs of psychiatric conditions. This is incongruent with reports from the Singapore Mental Health Study, which reported higher lifetime prevalence rates. ${ }^{42}$ One possible reason is that patients with psychiatric illnesses tend to consult spiritual healers for help instead of their primary care physicians. ${ }^{42}{ }^{43}$ Finally, we did not estimate the impact of each chronic condition on affected individuals. This was a criterion that was used by Fortin $e t$ al in his selection of chronic conditions for inclusion in their operational definition. ${ }^{21}$

\section{CONCLUSION}

We compared six operational definitions and found that Fortin et al's list of chronic conditions ${ }^{21}$ (online supplemental appendix 1-1) was most applicable to the primary care setting in Singapore, fulfilling the aforementioned criteria. We propose the addition of prediabetes and the chronic condition 'physical disability' into Fortin et $a l$ 's list of conditions ${ }^{21}$ to augment its comprehensiveness in our setting (online supplemental appendix 6).

Multimorbidity is a growing global healthcare conundrum. We used criteria previously proposed by Fortin et $a l^{21}$ in the formulation of a standardised operational definition contextualised to primary care in Singapore. The creation of such standardised operational definitions for use in individual countries would allow for meaningful comparisons to be made across research studies done within the country. Common patterns of multimorbidity within the country can then be reliably identified, facilitating the creation of specific multimorbidity CPGs that are relevant to the primary care setting of the country. The CPGs can focus on coordinating care across various specialties, medications management to avoid polypharmacy and management of shared disease risk factors that are not covered with the current single disease CPGs. ${ }^{44}$ We propose that similar studies be conducted in different geographical countries/regions in the world to describe the most suitable list of chronic conditions for multimorbidity in their own context.

Contributors ESL and PSSL initiated and conceptualised the study. ESL and YX developed the analysis approach. YAJL conducted the data analysis for this study. YAJL wrote the first draft of the manuscript. YX, PSSL and ESL provided inputs and assisted in the interpretation of the findings. ESL critically reviewed the final version of the article. All authors have read and approved the final manuscript. 
Funding This research was supported by the Singapore Ministry of Health's National Medical Research Council under the Centre Grant Programme (reference number CGAug16C019).

Competing interests None declared.

Patient consent for publication Not required.

Provenance and peer review Not commissioned; externally peer reviewed.

Data availability statement Data are available upon reasonable request. Data are not available for online access. Readers who wish to gain access to the data can write to the senior author ESL at NHGP_CRU@nhgp.com.sg with their requests. Access can be granted subject to approval of the National Healthcare Group Domain Specific Review Board (DSRB) and in line with the National Healthcare Group Research Data Policy. This is a requirement mandated for this research study by our DSRB and funders.

Supplemental material This content has been supplied by the author(s). It has not been vetted by BMJ Publishing Group Limited (BMJ) and may not have been peer-reviewed. Any opinions or recommendations discussed are solely those of the author(s) and are not endorsed by BMJ. BMJ disclaims all liability and responsibility arising from any reliance placed on the content. Where the content includes any translated material, BMJ does not warrant the accuracy and reliability of the translations (including but not limited to local regulations, clinical guidelines, terminology, drug names and drug dosages), and is not responsible for any error and/or omissions arising from translation and adaptation or otherwise.

Open access This is an open access article distributed in accordance with the Creative Commons Attribution Non Commercial (CC BY-NC 4.0) license, which permits others to distribute, remix, adapt, build upon this work non-commercially, and license their derivative works on different terms, provided the original work is properly cited, appropriate credit is given, any changes made indicated, and the use is non-commercial. See: http://creativecommons.org/licenses/by-nc/4.0/.

\section{ORCID iDs}

Yi An Janis Lee http://orcid.org/0000-0002-0541-2253

Poay Sian Sabrina Lee http://orcid.org/0000-0002-4660-514X

Eng Sing Lee http://orcid.org/0000-0003-4963-535X

\section{REFERENCES}

1 van den Akker M, Buntinx F, Roos S, et al. Problems in determining occurrence rates of multimorbidity. J Clin Epidemiol 2001;54:675-9.

2 King DE, Xiang J, Pilkerton CS. Multimorbidity trends in United States adults, 1988-2014. J Am Board Fam Med 2018;31:503-13.

3 Fortin M, Bravo G, Hudon C, et al. Prevalence of multimorbidity among adults seen in family practice. Ann Fam Med 2005;3:223-8.

4 Cassell A, Edwards D, Harshfield A, et al. The epidemiology of multimorbidity in primary care: a retrospective cohort study. Br J Gen Pract 2018;68:e245-51.

5 Ong KY, Lee PSS, Lee ES. Patient-Centred and not disease-focused: a review of guidelines and multimorbidity. Singapore Med J 2019

6 van den Akker M, Buntinx F, Knottnerus JA. Comorbidity or multimorbidity. Eur J Gen Pract 1996;2:65-70.

7 Nicholson K, Makovski TT, Griffith LE, et al. Multimorbidity and comorbidity revisited: Refining the concepts for international health research. J Clin Epidemiol 2019;105:142-6.

8 Muth C, Blom JW, Smith SM, et al. Evidence supporting the best clinical management of patients with multimorbidity and polypharmacy: a systematic guideline review and expert consensus. $J$ Intern Med 2019;285:272-88.

9 van den Akker M, Buntinx F, Metsemakers JF, et al. Multimorbidity in general practice: prevalence, incidence, and determinants of co-occurring chronic and recurrent diseases. J Clin Epidemiol 1998;51:367-75.

10 Marengoni A, Angleman S, Melis R, et al. Aging with multimorbidity: a systematic review of the literature. Ageing Res Rev 2011;10:430-9.

11 Ryan A, Wallace E, O'Hara P, et al. Multimorbidity and functional decline in community-dwelling adults: a systematic review. Health Qual Life Outcomes 2015:13:168.

12 Quah JHM, Wang P, Ng RRG, et al. Health-Related quality of life of older Asian patients with multimorbidity in primary care in a developed nation. Geriatr Gerontol Int 2017;17:1429-37.

13 France EF, Wyke S, Gunn JM, et al. Multimorbidity in primary care: a systematic review of prospective cohort studies. Br J Gen Pract 2012;62:e297-307.
14 Picco L, Achilla E, Abdin E, et al. Economic burden of multimorbidity among older adults: impact on healthcare and societal costs. BMC Health Serv Res 2016;16:173-73.

15 Starfield B. Challenges to primary care from Co- and multi-morbidity. Prim Health Care Res Dev 2011;12:1-2.

16 Hughes LD, McMurdo MET, Guthrie B. Guidelines for people not for diseases: the challenges of applying UK clinical guidelines to people with multimorbidity. Age Ageing 2013;42:62-9.

17 Pefoyo AJK, Bronskill SE, Gruneir A, et al. The increasing burden and complexity of multimorbidity. BMC Public Health 2015;15:415.

18 Fortin M, Stewart M, Poitras M-E, et al. A systematic review of prevalence studies on multimorbidity: toward a more uniform methodology. Ann Fam Med 2012;10:142-51.

19 Fortin M, Soubhi H, Hudon C, et al. Multimorbidity's many challenges. BMJ 2007;334:1016-7.

20 The Lancet. Making more of multimorbidity: an emerging priority. Lancet 2018;391:1637.

21 Fortin M, Almirall J, Nicholson K. Development of a research tool to document self-reported chronic conditions in primary care. J Comorb 2017;7:117-23.

22 Subramaniam M, Abdin E, Picco L, et al. Multiple chronic medical conditions: prevalence and risk factors--results from the Singapore Mental Health Study. Gen Hosp Psychiatry 2014;36:375-81.

23 Ge L, Yap CW, Heng BH. Sex differences in associations between multimorbidity and physical function domains among communitydwelling adults in Singapore. PLoS One 2018;13:e0197443.

24 Low LL, Kwan YH, Ko MSM, et al. Epidemiologic characteristics of multimorbidity and sociodemographic factors associated with multimorbidity in a rapidly aging Asian country. JAMA Netw Open 2019;2:e1915245.

25 Nguyen H, Manolova G, Daskalopoulou C, et al. Prevalence of multimorbidity in community settings: a systematic review and meta-analysis of observational studies. J Comorb 2019;9:2235042X19870934

$26 \mathrm{Ge} \mathrm{L}$, Ong R, Yap CW, et al. Effects of chronic diseases on healthrelated quality of life and self-rated health among three adult age groups. Nurs Health Sci 2019;21:214-22.

27 Department of Statistics, Ministry of Trade \& Industry, Republic of Singapore. Population trends. Singapore, 2016.

28 Ministry of Health S. Health service utilization 2016, 2016.

29 Singapore. Personal data protection act 2012, 2012.

30 O'Halloran J, Miller GC, Britt H. Defining chronic conditions for primary care with ICPC-2. Fam Pract 2004;21:381-6.

31 Johnston MC, Crilly M, Black C, et al. Defining and measuring multimorbidity: a systematic review of systematic reviews. Eur $\mathrm{J}$ Public Health 2019;29:182-9.

32 The Academy of Medical Sciences. Multimorbidity: a priority for global health research, 2018.

33 Coggon D, Rose G, Barker D. Epidemiology for the uninitiated. BMJ 1978.

34 Naing NN. Easy way to learn standardization : direct and indirect methods. Malays J Med Sci 2000;7:10-15.

35 Ministry of Health S. Chronic Disease Management Programme. In: Handbook for healthcare professionals. 88. Ministry of Health S ed. Singapore: Ministry of Health, Singapore, 2018.

36 Ministry of Health S. Top 4 conditions of Polyclinic attendances. Attendances TCoP ed, 2018.

37 Harrison C, Britt H, Miller G, et al. Examining different measures of multimorbidity, using a large prospective cross-sectional study in Australian general practice. BMJ Open 2014;4:e004694.

38 Wang P, Abdin E, Shafie S, et al. Estimation of prevalence of osteoporosis using OSTA and its correlation with sociodemographic factors, disability and comorbidities. Int $J$ Environ Res Public Health 2019;16:ijerph16132338. doi:10.3390/ ijerph16132338

39 Ministry of Health S. War on Diabetes - Summary Report 2016-2019. 30. Singapore, 2019.

40 Ho EC, Zhang H, Ong WMW, et al. Hearing impairment and hearing aid usage in Singapore. Int $J$ Audiol 2018;57:291-301.

41 Gontijo Guerra S, Berbiche D, Vasiliadis H-M. Measuring multimorbidity in older adults: comparing different data sources. BMC Geriatr 2019;19:166.

42 Institute of Mental Health S. Latest study sheds light on the state of mental health in Singapore. Singapore, 2011.

43 Wang PS, Berglund PA, Olfson M, et al. Delays in initial treatment contact after first onset of a mental disorder. Health Serv Res 2004;39:393-416.

44 Wallace E, Salisbury C, Guthrie B, et al. Managing patients with multimorbidity in primary care. BMJ 2015;350:h176. 